\title{
Anti-Obesity Effect of a Mixture of Skim Milk, Red Ginseng Extract, and Black Raspberry Extract Fermented with Lactobacillus acidophilus on High-Fat Diet-Fed Obese Mice
}

Eun Ji Yum ${ }^{1}$, Nam Keun Lee ${ }^{1,2^{*}}$, Jisun $\mathrm{Oh}^{3}$, Chang Hyun Lee ${ }^{4}$, Mi Jin Oh ${ }^{5}$, Ha-Rim Kim ${ }^{6}$, Chan-Ho Oh${ }^{6}$, Jong-Hyuk Park Hye-Jung Moon ${ }^{7}$ and Yong-Seob Jeong ${ }^{1^{*}}$

${ }^{1}$ Department of Food Science and Technology, Chonbuk National University, Jeonju 561-756, Korea

${ }^{2}$ Research Center for Industrial Development of Biofood Materials, Chonbuk National University, Jeonju 561-756, Korea

${ }^{3}$ School of Food Science and Biotechnology (BK21 Plus), Kyungpook National University, Daegu 702-701, Korea

${ }^{4}$ College of Oriental Medicine, Woosuk University, Wanju 565-701, Korea

${ }^{5}$ Korea Food Research Institute, Seongnam 13539, Korea

${ }^{6}$ College of Food Science, Woosuk University, Wanju 565-701, Korea

${ }^{7}$ Imsil Research Institute of Cheese Science, Imsil 566-881, Korea

Correspondence to:

Yong-Seob Jeong

Department of Food Science and Technology

Chonbuk National University, Korea

E-mail: ysjeong@jbnu.ac.kr

\section{Nam Keun Lee}

Department of Food Science and Technology

Chonbuk National University, Korea

Tel: +82-63-270-2571, +82-63-270-4819

Fax: +63-270-4344

E-mail: nklee@jbnu.ac.kr

Received: September 25, 2015

Accepted: February 02, 2016

Published: March 10, 2016

Citation: Yum EJ, Lee NK, Oh J, Lee CH, Oh MJ, et al. 2016. Anti-Obesity Effect of a Mixture of Skim Milk, Red Ginseng Extract, and Black Raspberry Extract Fermented with Lactobacillus acidophilus on High-Fat Diet-Fed Obese Mice. J Food Chem Nanotechnol 2(2): 66-72.

Copyright: (C) 2016 Yum et al. This is an Open Access article distributed under the terms of the Creative Commons Attribution 4.0 International License (CC-BY) (http://creativecommons. org/licenses/by/4.0/) which permits commercial use, including reproduction, adaptation, and distribution of the article provided the original author and source are credited.

Published by United Scientific Group

\section{Abstract}

The aim of this study was to assess the anti-obesity effect of Lactobacillus acidophilus-fermented mixture of skim milk, red ginseng extract, and immature fruit of Rubus coreanus Miquel (called black raspberry) extract in a mouse model of diet-induced obesity. Male C57BL/6J mice were fed a normal diet (ND), high-fat diet (HFD), high-fat diet supplemented with fermented skim milk (HFD-FSM), or high-fat diet supplemented with the fermented mixture (HFDFMIX). FSM and FMIX were orally administered ( $2 \mathrm{~g} / \mathrm{kg}$ of body weight) on a daily basis. Following a 6-week regimen, the following physical and biochemical measures were assessed: feed intake, body weight, periepididymal fat and perirenal fat mass, size of the epididymal adipocytes, and plasma levels of glucose, insulin, adiponectin, and leptin. No significant differences were observed in all parameters tested in the HFD-fed and HFD-FSM-fed groups, except the plasma leptin level, which was higher in the HFD-FSM-fed group than in the HFD-fed group. In the HFD-FMIX-fed group, feed intake was similar to, but the adiponectin level was higher than that in the HFD-fed group. The HFD-FMIX-fed group showed significantly lower increase in body weight, size of epididymal adipocytes, and plasma levels of glucose and leptin than the HFD-fed group. These results demonstrate that the obesity-related measures can be decreased in obese mice by administration of L. acidophilus-fermented mixture of skim milk, red ginseng, and black raspberry fruit extract. These results also suggest that the fermented mixture can possibly be utilized as a functional food material with an anti-obesity effect.

\section{Keywords}

Fermentation, Lactobacillus acidophilus, Red ginseng, Black raspberry, Antiobesity

\section{Introduction}

Obesity results from energy imbalance caused by excessive intake of highcalorie foods and lack of exercise. It is generally accompanied by metabolic disorders that can cause various diseases such as diabetes, cardiovascular disease, hypertension, hyperlipidemia, and cancers [1]. Thus, several therapeutic strategies, such as behavior modification, exercise, dietary remedies, medications, and surgery, have been developed. Since modification of one's lifestyle helps overcome energy imbalance and subsequent disorders, supplementation with anti-obesity 
functional foods has garnered attention for obesity treatment.

Red ginseng is a medicinal herb that has health beneficial effects including anti-obesity effects. Several groups reported that the anti-obesity effect is attributed to ginseng saponins [2-4], which are classified into protopanaxadiol group (ginsenosides: $\mathrm{Ra}, \mathrm{Rb}, \mathrm{Rc}, \mathrm{Rd}, \mathrm{Rg} 3$, Rh2, and Rs) and protophanxatriol group (ginsenosides: $\mathrm{Re}, \mathrm{Rf}, \mathrm{Rg} 1, \mathrm{Rg} 2$, and Rh1) depending on their chemical structures. Red ginseng is known to contain large amounts of Rg2, Rg3, Rh1, and Rh2 ginsenosides that are effectively produced during the heating process. $\mathrm{Rg} 3$ and $\mathrm{Rh} 2$ ginsenosides have anti-obesity effects in vitro $[3,4]$.

Black raspberry (Rubus coreanus Miquel; called 'Bokbunja' in Korean) is traditionally used to help restore stamina [5]. Studies have reported that the dried immature fruit is commonly prescribed for various diseases in oriental medicine. In addition, multiple studies have demonstrated the diverse effects of the fruits i.e., the antioxidant effect [6], lipid metabolism enhancing effect [7], and weight control [8].

Lactic acid bacteria (LAB) are representative microorganisms used as probiotics owing to their essential benefits to intestinal health. Since various reports have demonstrated the correlation between intestinal health and obesity development, the anti-obesity effect of LAB or LAB supplementation as a bio-functional material is also extensively studied [9-12].

In this study, a mixture of skim milk powder, ginseng extract, and immature black raspberry extract was fermented by Lactobacillus acidophilus isolated from kimchi. The fermented extract was then administered to high-fat diet-induced obese mice. Following a 6-week regimen, various physical and biochemical measures, such as food intake, body weight, periepididymal fat and perirenal fat mass, size of epididymal adipocytes, and plasma levels of glucose, insulin, adiponectin, and leptin were assessed.

\section{Materials and Methods}

\section{Samples and preparation}

L. acidophilus of LAB and black raspberry (dried immature fruit) were obtained from Imsil Research Institute of Cheese Science (Seongsu-myeon, Imsil-gun, Korea) and Berry and Biofood Research Institute (Buan-myeon, Gochang-gun, Korea), respectively. Nonfat dry milk and red ginseng extract were purchased from Seoul Dairy Cooperative (Seoul, Korea) and Kunbo Co., Ltd. (Jinan-gun, Korea), respectively. Black raspberry $(200 \mathrm{~g})$ was extracted in water $(6 \mathrm{~L})$ for $9 \mathrm{~h}$ at $100{ }^{\circ} \mathrm{C}$, and then the extracts were freeze-dried.

\section{Analysis of free amino acids}

The sample $(1 \mathrm{~g})$ was extracted in $70 \%$ ethanol $(50 \mathrm{~mL})$ for $15 \mathrm{~min}$ at $80{ }^{\circ} \mathrm{C}$. After duplicating the extraction, the extracts were filtered and ethanol was evaporated with a rotary vacuum evaporator. The resulting water solution was mixed with ether and then passed through a separating funnel to remove the ether layer. The extracts obtained were dried in a rotary evaporator. After the extract powder was solubilized in sample dilution buffer $(10 \mathrm{~mL})$, the amino acid contents were determined using an amino acid analyzer (Sykam S433, Sykam $\mathrm{GmbH}$, Eresing, Germany), according to the manufacturer's instructions.

\section{Experimental animals and feed}

Twenty-four C57BL/6J mice ( $25 \mathrm{~g}$, male) were purchased from Damul-Science (Daejeon, Korea). After 1-week adaptation under a $12-\mathrm{h}$ light/12-h dark cycle (temperature, $20-24{ }^{\circ} \mathrm{C}$; humidity, $\left.45-55 \%\right), 8$-week old mice were used in this study. The mice were divided into 4 groups (6 mice per group) using a randomized block design. For 6 weeks, each group was fed different diets; (1) normal diet (ND), (2) high fat diet (HFD), (3) HFD with fermented 10\% skim milk diet (HFD-FSM, fermented by L. acidophilus at $37^{\circ} \mathrm{C}$ for $72 \mathrm{~h}$ ) and (4) HFD with fermented mixture (HFD-FMIX, fermented by L. acidophilus at $37^{\circ} \mathrm{C}$ for $72 \mathrm{~h}$ ) (Table 1). The mixture consisted of $10 \% \mathrm{w} / \mathrm{w}$ skim milk and $2 \% \mathrm{w} / \mathrm{w}$ mixture $(1 \% \mathrm{w} / \mathrm{w}$ red ginseng extract and $1 \% \mathrm{w} / \mathrm{w}$ black raspberry extract). Before administration to the mice, the skim milk powder and mixture powder were freshly dissolved in drinking water.

\begin{tabular}{|c|c|c|c|c|}
\hline \multicolumn{5}{|c|}{ ble 1: Composition of experimental die } \\
\hline Ingredients & $\mathbf{N D}^{\mathrm{a})}$ & HFD $^{\mathrm{b})}$ & $\begin{array}{l}\text { HFD- } \\
\text { FSM }^{\text {c) }}\end{array}$ & $\begin{array}{l}\text { HFD- } \\
\text { FMIX }^{\mathrm{d})}\end{array}$ \\
\hline Casein & 200.00 & 233.07 & 224.14 & 224.14 \\
\hline Sucrose & 100.00 & 201.38 & 195.73 & 175.73 \\
\hline Dextrose & 132.00 & 116.54 & 116.54 & 116.54 \\
\hline Corn Starch & 397.50 & 84.84 & 0.00 & 0.00 \\
\hline Cellulose & 50.00 & 58.27 & 58.27 & 58.27 \\
\hline Soybean Oil & 70.00 & 29.13 & 29.13 & 29.13 \\
\hline Fermented Skim milk & 0.00 & 0.00 & 100.00 & 100.00 \\
\hline Red Ginseng Extract & 0.00 & 0.00 & 0.00 & 10.00 \\
\hline Black Raspberry Extract & 0.00 & 0.00 & 0.00 & 10.00 \\
\hline Lard & 0.00 & 206.85 & 206.26 & 206.26 \\
\hline Mineral (Ca.P free) & 35.00 & 52.44 & 52.44 & 52.44 \\
\hline Vitamin Mix & 10.00 & 11.65 & 11.65 & 11.65 \\
\hline L-Cystine & 3.00 & 3.50 & 3.50 & 3.50 \\
\hline Choline Bitartrate & 2.50 & 2.33 & 2.33 & 2.33 \\
\hline $\begin{array}{l}\text { a) ND: normal diet group } \\
\text { b)HFD: high fat-diet } 45 \\
\text { c)HFD-FSM: HFD witl } \\
\text { (FSM) diet } \\
\text { d)HFD-FMIX: HFD wi } \\
\text { skim milk, 1\% red ginser } \\
\text { diet group }\end{array}$ & $\begin{array}{l}1 \% \text { IN-93C } \\
\text { fermente } \\
\text { fermen } \\
\text { extract, }\end{array}$ & $\begin{array}{l}\text { freeze- } \\
\text { ed freeze } 1 \% \text { b }\end{array}$ & $\begin{array}{l}\text { d } 10 \% \\
\text { ied mix } \\
\text { raspbe }\end{array}$ & $\begin{array}{l}\text { milk powder } \\
\text { owder ( } 10 \% \\
\text { ract: FMIX) }\end{array}$ \\
\hline
\end{tabular}

The HFD-FSM and HFD-FMIX groups were fed an HFD, and orally administered FSM and FMIX in water at $2 \mathrm{~g} / \mathrm{kg}$ body weight (BW) on a daily basis, respectively. The same volume of drinking water was orally administered to the mice in the ND and HFD groups.

Amount of dietary intake and feed efficiency and body weight

Dietary intake of mice was regularly measured once a 
week for 6 weeks. Feed efficiency was calculated by dividing the weight gain by the dietary intake. The body weight was daily monitored at 10:00 am for a week from the first experiment day. The change in body weight was calculated by the following equation:

Feed efficiency ratio $=$ Weight gain $(\mathrm{g}) /$ Dietary intake $(\mathrm{g})$

Fat gain and change in the fat cell size

At the end of the experiment, the periepididymal fat and perirenal fat were obtained from each group and weighed to check the amount of fat gain. Some epididymal adipocytes were fixed with Bouin's solution and soaked in $20 \%$ sucrose overnight, and then $20-\mu \mathrm{m}$ frozen sections were obtained for Oil Red O staining using the free floating method to observe the changes in the adipocyte size.

Change in the blood glucose and levels of obesity-related hormones in the serum

After the end of the experiment, mice from each group were sacrificed and their blood was collected to measure the blood glucose level using the blood analysis kit (Asan Pharm, Seoul, Republic of Korea), and the anti-obesity effect was observed physiologically.

ELISA analysis was conducted to observe the physiological anti-obesity effect of adiponectin, which includes adipocyte differentiation-related hormone in the serum (using mouse/ rat adiponectin ELISA kit, Shibayagi, Japan), leptin (using mouse leptin ELISA kit, KOMA Biotech, Korea), and insulin (using mouse insulin ELISA kit, Shibayagi, Japan). The concentration of adiponectin in the blood was measured by Enavall and Perlmann method [13] using mouse/rat adiponectin ELISA kit (Shibayagi Co., Ltd, Japan). All the analyses were conducted following the manufacturer's instructions. The absorbance was measured at $450 \mathrm{~nm}$ using ELISA reader.

\section{Statistical analysis}

All results were expressed as the average and standard deviation using SPSS 12.0 for Windows (SPSS Inc., USA), and one-way analysis of variance (ANOVA) was applied. In order to verify the differences between each group, non-paired $t$-test was performed. The significance was assessed at $\mathrm{p}<0.05$.

\section{Results}

\section{Change in body weight, dietary intake, and feed efficiency}

After 6 weeks, the body weights of the mice were measured and compared among the groups (Figure 1). The average body weight per mouse in the ND and HFD groups was $5.42 \pm 1.43 \mathrm{~g}$ (22.6\% increase compared to that before the experiment) and $8.94 \pm 3.01 \mathrm{~g}(37.9 \%$ increase compared to that before the experiment), respectively. The body weight of HFD-induced obese mice significantly increased by $64.9 \%$ compared to that reported for the ND group mice (\#, $\mathrm{p}<0.01$ ). The body weights in the HFD-FSM and HFD-FMIX groups were $8.09 \pm 1.88 \mathrm{~g}$ (33.4\% increase compared to that before the experiment) and $5.42 \pm 1.02 \mathrm{~g}(22.5 \%$ increase compared to that before the experiment), respectively. The weight of mice in the HFDFMIX group significantly decreased by $39.4 \%$ compared to

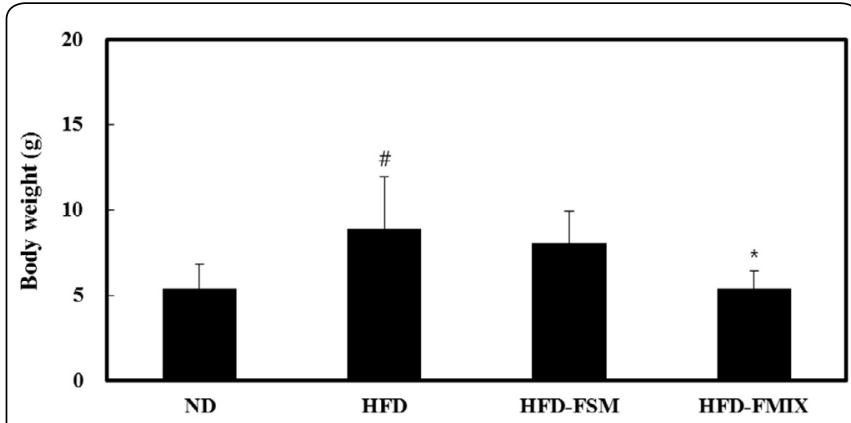

Figure 1: Total body weight of mice fed experimental diets for 6 weeks. ND, normal diet group; HFD, high-fat diet group; HFD-FSM, high-fat diet containing fermented skim milk (L. acidophilus and 10\% skim milk); HFDFMIX, high-fat diet containing the fermented mixture (L. acidophilus, $10 \%$ skim milk, $2 \%$ red ginseng concentrate, and Rubus coreanus Miquel extract). Values are significantly different from the normal group (ND) (\#) and control group $(\mathrm{HFD})\left(^{*}\right) ; \#, \mathrm{p}<0.01{ }^{*}, \mathrm{p}<0.01$.

Table 2: The effect of HFD-FSM and HFD-FMIX on daily body weight and feed intake, and feed efficiency ratio (FER) in high fat diet-fed mice.

\begin{tabular}{|c|c|c|c|}
\hline Groups & $\begin{array}{c}\text { Increase in the } \\
\text { daily body weight }(\mathrm{g})\end{array}$ & Daily feed intake $(\mathrm{g})$ & $\begin{array}{c}\text { Feed efficiency } \\
\text { ratio }\end{array}$ \\
\hline ND & $0.13 \pm 0.04^{1)}$ & $3.06 \pm 0.16$ & 0.042 \\
\hline HFD & $0.21 \pm 0.04^{\# 2)}$ & $2.72 \pm 0.14^{\#}$ & $0.077^{\#}$ \\
\hline HFD-FSM & $0.19 \pm 0.03$ & $2.77 \pm 0.10$ & 0.068 \\
\hline HFD-FMIX & $0.13 \pm 0.06^{* 3)}$ & $2.74 \pm 0.19$ & $0.047^{*}$ \\
\hline
\end{tabular}

${ }^{1)}$ Values represent the mean \pm s.d. $(n=6$ /group) of mice fed experimental diets for 6 weeks

${ }^{2)}$ Values are significantly different from the normal group (ND) (\#, p $\left.<0.01\right)$

${ }^{3)}$ Values are significantly different from the control group (HFD) $(*, p<0.05)$

that reported for the HFD group mice $\left(^{*}, \mathrm{p}<0.01\right)$.

Dietary intake and feed efficiency are shown in Table 2. The daily feed intake in the ND and HFD groups was 3.06 $\pm 0.16 \mathrm{~g}$ and $2.72 \pm 0.14 \mathrm{~g}$ per mouse, respectively, showing significant reduction in the HFD group compared to the ND group (\#, $\mathrm{p}<0.01)$. The feed intake in the HFD-FSM group and HFD-FMIX group was $2.77 \pm 0.10 \mathrm{~g}$ and $2.74 \pm 0.19 \mathrm{~g}$, respectively.

The feed efficiencies of the ND and HFD groups were 0.042 and 0.077 , respectively. The feed efficiency of the HFD group was significantly higher than that of the ND group (\#, $\mathrm{p}<0.01)$. The feed efficiencies of the HFD-FSM and HFDFMIX groups were 0.068 and 0.047 , respectively. The feed efficiency of the HFD-FMIX group was significantly lower than that of the HFD group $\left({ }^{*}, \mathrm{p}<0.01\right)$.

\section{Fat gain and change in the fat cell size}

The weights of periepididymal fat and perirenal fat after the 6-week experimental period are shown in Figure 2. Periepididymal fat weight was $0.39 \pm 0.105 \mathrm{~g}$ in the ND group and $0.66 \pm 0.278 \mathrm{~g}$ in the HFD group, showing $69.2 \%$ weight gain in the HFD group relative to the ND group. The weight of periepididymal fat in the HFD-FMIX group was $29.4 \%$ lower than that in the HFD group. The weights of perirenal fat in the ND group and HFD group were $0.06 \pm 0.032 \mathrm{~g}$ 


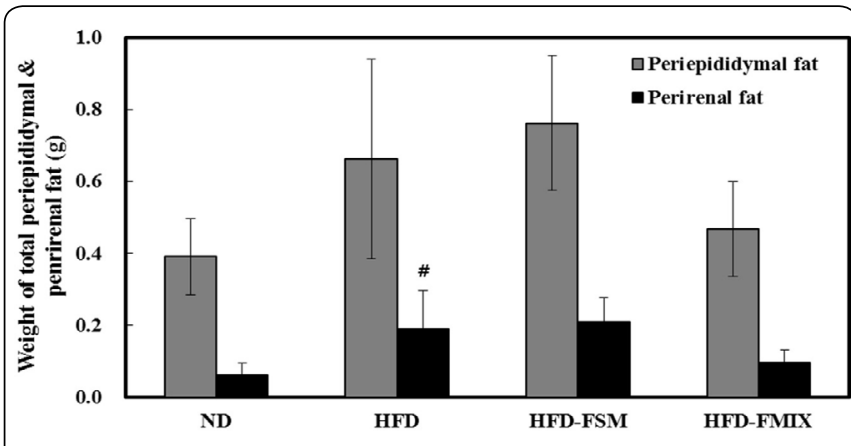

Figure 2: Periepididymal and perirenal fat weight of mice fed experimental diets for 6 weeks. ND, normal diet group; HFD, high-fat diet group; HFDFSM, high-fat diet containing fermented skim milk (L. acidophilus and 10\% skim milk); HFD-FMIX, high-fat diet containing the fermented mixture (L. acidophilus, $10 \%$ skim milk, $2 \%$ red ginseng concentrate, and Rubus coreanus Miquel extract). Values are significantly different from the normal group (ND) (\#) and control group (HFD) $\left({ }^{*}\right) ; \#, p<0.05$.

and $0.19 \pm 0.108 \mathrm{~g}$, respectively. The perirenal fat weight of the HFD group significantly increased by $67 \%$ compared to that observed for the ND group $(\#, p<0.05)$. The perirenal fat weight of the HFD-FMIX group $(0.09 \pm 0.036 \mathrm{~g})$ decreased by $50 \%$ compared to that reported for the HFD group; however, it was not significantly different. In conclusion, the total weight gain of periepididymal fat and perirenal fat in the ND group and HFD group was $0.45 \pm 0.138 g$ and $0.85 \pm$ $0.385 \mathrm{~g}$ per mouse, respectively. The total fat weight of the HFD group increased by $88.0 \%$ compared to that reported for the ND group. In the HFD-FSM group and HFD-FMIX group, the total weights were $0.97 \pm 0.249 \mathrm{~g}$ and $0.56 \pm 0.167 \mathrm{~g}$ per mouse, respectively. The total fat weight of the HFD-MIX group decreased by $34.1 \%$ compared to that reported for the HFD group.

The change in the adipocyte size is shown in Figure 3. The adipocyte size in the HFD group increased compared to that in the ND group. In the HFD-FMIX group, the size of the adipocytes decreased compared to the HFD group or HFDFSM group.

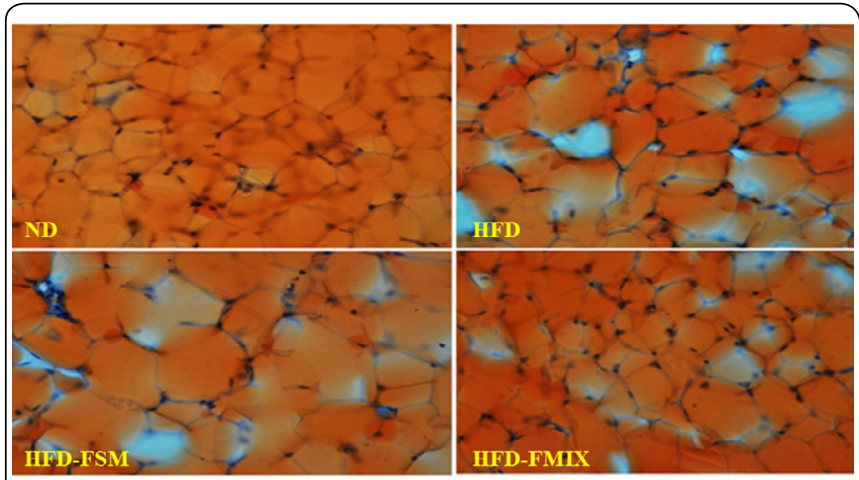

Figure 3: The size of the adipocytes in periepididymal fat in mice fed experimental diets for 6 weeks. ND, normal diet group; HFD, high-fat diet group; HFD-FSM, high-fat diet containing fermented skim milk (L. acidophilus and $10 \%$ skim milk); HFD-FMIX, high-fat diet containing the fermented mixture (L. acidophilus, $10 \%$ skim milk, $2 \%$ red ginseng concentrate, and Rubus coreanus Miquel extract).

\section{Change in blood glucose level}

At the end of the 6-week study, the serum glucose

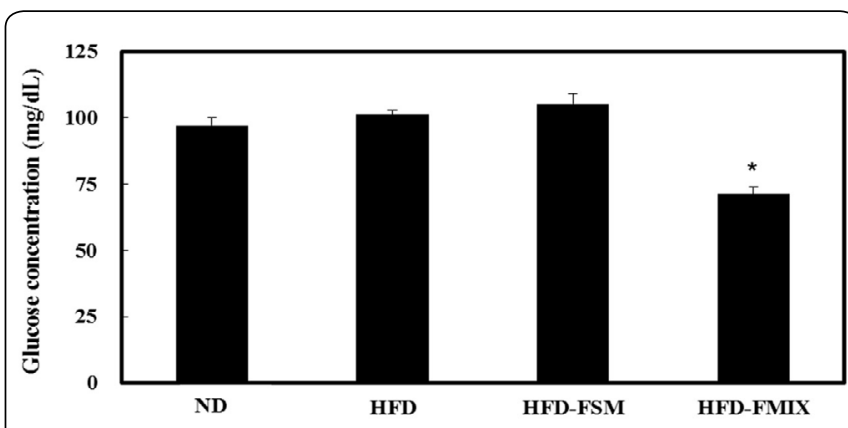

Figure 4: Serum glucose concentration in mice fed experimental diets for 6 weeks. ND, normal diet group; HFD, high-fat diet group; HFD-FSM, high-fat diet containing fermented skim milk (L. acidophilus and 10\% skim milk); HFDFMIX, high-fat diet containing the fermented mixture (L. acidophilus, $10 \%$ skim milk, $2 \%$ red ginseng concentrate, and Rubus coreanus Miquel extract). Values are significantly different from the normal group (ND) (\#) and control group $(\operatorname{HFD})\left({ }^{*}\right) ;{ }^{* *}, \mathrm{p}<0.01$.

concentration was measured and is shown in Figure 4. The concentration of serum glucose was $97.2 \pm 2.8 \mathrm{mg} / \mathrm{dL}$ in the ND group and $101.3 \pm 1.7 \mathrm{mg} / \mathrm{dL}$ in the HFD group. There was no significant difference in the serum glucose level between the ND and HFD groups. The serum glucose level in the HFD-FSM group and HFD-FMIX group was $105.3 \pm$ $3.8 \mathrm{mg} / \mathrm{dL}$ and $71.3 \pm 2.7 \mathrm{mg} / \mathrm{dL}$, respectively, whereas that in the HFD-FMIX group was significantly lower than the levels in the HFD group $\left(^{*}, \mathrm{p}<0.01\right)$.

Change in serum levels of adipocyte-related proteins and hormones

After the 6-week experiment, the serum concentration of leptin, adiponectin, and insulin was evaluated and is shown in Figure 5. The concentrations of leptin in the ND, HFD, HFDFSM, and HFD-FMIX groups were $480.0 \pm 8.5 \mathrm{pg} / \mathrm{mL}, 607.5$ $\pm 12.5 \mathrm{pg} / \mathrm{mL}, 896.6 \pm 29.4 \mathrm{pg} / \mathrm{mL}$, and $243.0 \pm 2.5 \mathrm{pg} / \mathrm{mL}$, respectively. The leptin levels in the HFD group significantly increased compared to that in the ND group (\#\#, $\mathrm{p}<0.01$ ). In contrast, the leptin levels in the HFD-FMIX group significantly decreased by $60.0 \%$ compared to that in HFD group (***, $\mathrm{p}<0.001)$.

The serum adiponectin concentrations in the ND group and $\mathrm{HFD}$ groups were $27.47 \pm 0.56 \mu \mathrm{g} / \mathrm{mL}$ and $10.43 \pm 0.53$ $\mu \mathrm{g} / \mathrm{mL}$, respectively. The adiponectin concentration in the HFD group was significantly lower than that in the ND group (\#\#, p < 0.001). The adiponectin concentrations in the HFD-FSM group and HFD-FMIX group were $9.23 \pm 1.36 \mu \mathrm{g} / \mathrm{mL}$ and $14.18 \pm$ $1.43 \mu \mathrm{g} / \mathrm{mL}$, respectively. The HFD-FMIX group exhibited $36.0 \%$ increase in adiponectin concentration compared to the HFD group (**, $\mathrm{p}<0.01)$. The serum insulin concentrations in the ND, HFD, HFD-FSM, and HDF-FMIX groups were $10.5 \pm 0.1 \mu \mathrm{IU} / \mathrm{mL}, 52.4 \pm 0.9 \mu \mathrm{IU} / \mathrm{mL}, 53.4 \pm 1.3 \mu \mathrm{IU} /$ $\mathrm{mL}$, and $48.2 \pm 0.2 \mu \mathrm{IU} / \mathrm{mL}$, respectively. The insulin level in the HFD group significantly increased to $399.0 \%$ compared to that in the ND group (\#, p < 0.05). The HFD-FMIX group exhibited significant reduction $(8.0 \%)$ in insulin level compared to the HFD group (*, p < 0.05).

\section{Free amino acid content in the FSM and FMIX}

Amino acids in FSM and FMIX are the major fermentation products with anti-obesity effects in this study. 


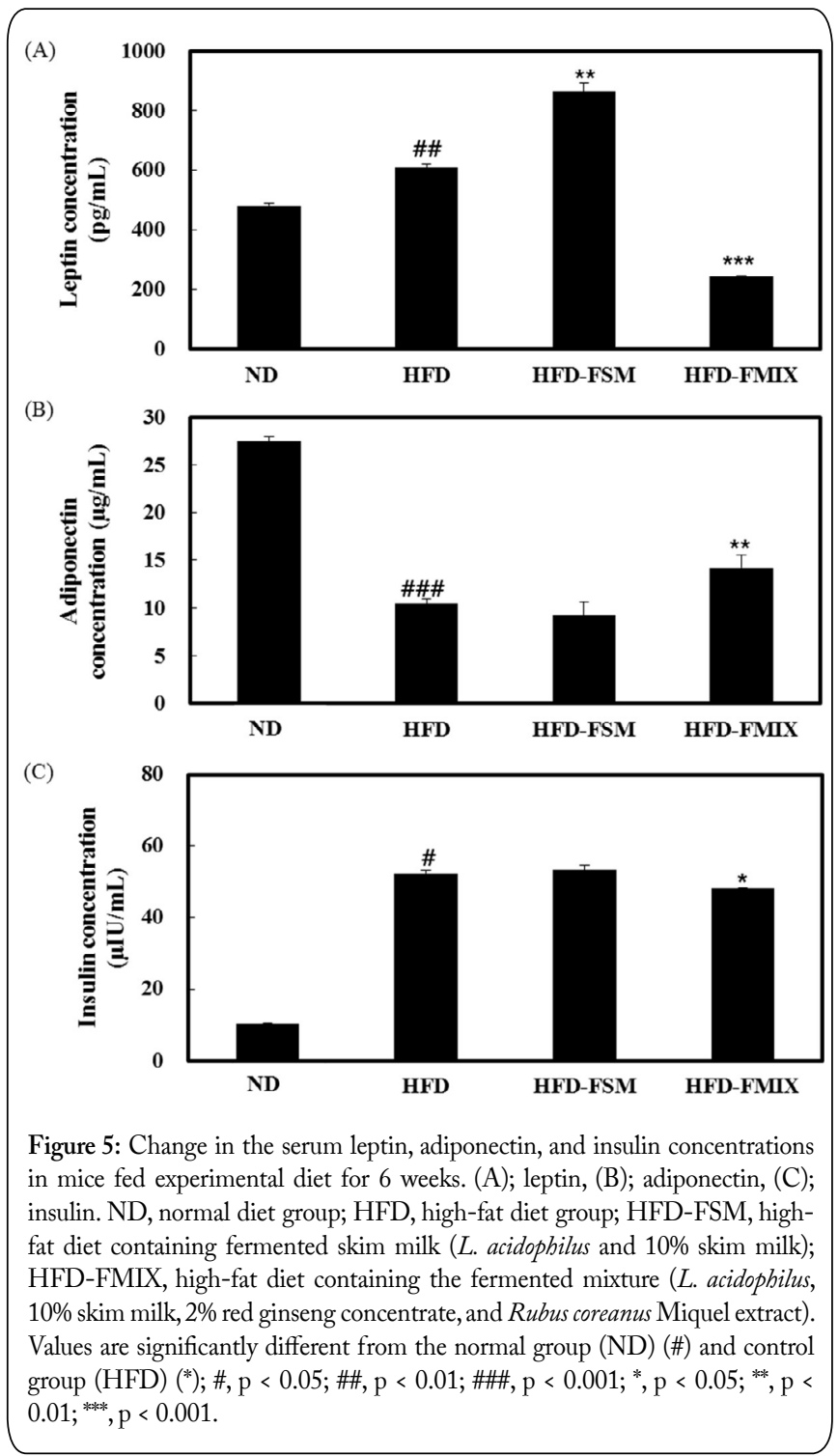

The content of total free amino acids in FSM and FMIX was $4844.18 \mathrm{mg} / \mathrm{L}$ and $6341.28 \mathrm{mg} / \mathrm{L}$, respectively (Table 3). Among the eighteen different free amino acids, the content of seven amino acids (aspartic acid, threonine, serine, asparagine, GABA, ornithine, and arginine) in FMIX was significantly different from that in FSM. Out of the seven free amino acids in FMIX, arginine was detected at a higher level, $836.28 \mathrm{mg} / \mathrm{L}$.

\section{Discussion}

In this study, the anti-obesity effect of the mixture of skim milk, red ginseng, and raspberry extract fermented by Kimchiderived $L$. acidophilus was evaluated in vivo. Adult mice were administered the fermented mixture for 6 weeks and various obesity-related physical and biochemical measures were tested. The results demonstrated that (1) supplementation with the fermented mixture reduced body weight, total fat weight, and adipocyte size in obesity-induced mice, and (2) administration of the fermented mixture to obese mice increased the level of plasma adiponectin and decreased the levels of plasma leptin and insulin.

Leptin is positively correlated with the adipocyte size [14,
15], but plasma adiponectin is negatively correlated with leptin, fasting insulin concentration, body mass index (BMI), and fat mass [16-18]. Adiponectin, an adipocytokine produced by adipocytes, activates energy metabolism by increasing insulin sensitivity and promotes fat oxidation of skeletal muscle [1921]. Thus, the elevated plasma adiponectin level in the HFDFMIX group may be correlated with reduced body weight and fat mass.

\begin{tabular}{|c|c|c|c|}
\hline Amino acid & SM-MIX ${ }^{1)}$ & FSM $^{2)}$ & FMIX $^{3)}$ \\
\hline Aspartic Acid & $\begin{array}{c}240.10 \pm 4.80 \\
\text { b3) }\end{array}$ & $\mathrm{ND}^{4)}$ & $460.54 \pm 21.31^{a}$ \\
\hline Threonine & $48.23 \pm 6.13^{\mathrm{b}}$ & $169.79 \pm 9.03^{c}$ & $219.06 \pm 43.67^{a}$ \\
\hline Serine & $119.94 \pm 0.44^{b}$ & $65.85 \pm 3.85^{\mathrm{c}}$ & $167.74 \pm 34.62^{\mathrm{a}}$ \\
\hline Asparagine & $\begin{array}{c}1261.64 \pm \\
45.64^{\mathrm{a}}\end{array}$ & ND & $\begin{array}{c}1143.82 \pm \\
18.18^{\mathrm{b}}\end{array}$ \\
\hline Glutamic Acid & $236.61 \pm 21.88^{c}$ & $\begin{array}{c}1264.84 \pm \\
51.52^{\mathrm{a}}\end{array}$ & $942.88 \pm 30.71^{b}$ \\
\hline Glycine & $42.48 \pm 3.13^{\mathrm{b}}$ & $131.29 \pm 4.81^{\mathrm{a}}$ & $145.99 \pm 27.20^{a}$ \\
\hline Alanine & $119.62 \pm 7.53^{c}$ & $669.39 \pm 26.97^{a}$ & $476.19 \pm 87.46^{b}$ \\
\hline Valine & $73.08 \pm 23.32^{c}$ & $378.14 \pm 13.49^{a}$ & $294.63 \pm 74.60^{b}$ \\
\hline Methionine & ND & $54.61 \pm 6.73$ & ND \\
\hline Isoleucine & $37.78 \pm 2.52^{\mathrm{c}}$ & $164.51 \pm 5.66^{\mathrm{a}}$ & $132.20 \pm 29.56^{b}$ \\
\hline Leucine & $64.45 \pm 3.81^{\mathrm{c}}$ & $750.88 \pm 25.91^{\mathrm{a}}$ & $587.34 \pm 45.27^{b}$ \\
\hline Tyrosine & $48.13 \pm 1.18^{\mathrm{b}}$ & $125.33 \pm 6.47^{a}$ & $107.95 \pm 25.49^{a}$ \\
\hline Phenylalanine & $33.83 \pm 2.28^{\mathrm{b}}$ & $283.41 \pm 11.07^{a}$ & $261.30 \pm 51.65^{a}$ \\
\hline GABA & $170.90 \pm 4.47^{\mathrm{b}}$ & ND & $309.72 \pm 19.99^{a}$ \\
\hline Histidine & ND & $145.81 \pm 4.96^{\mathrm{a}}$ & $67.14 \pm 12.25^{b}$ \\
\hline Ornithine & $8.55 \pm 1.16^{\mathrm{b}}$ & $8.03 \pm 0.89^{b}$ & $20.44 \pm 4.72^{\mathrm{a}}$ \\
\hline Lysine & $29.35 \pm 1.00^{\mathrm{b}}$ & $317.97 \pm 11.04^{\mathrm{a}}$ & $168.06 \pm 31.99^{b}$ \\
\hline Arginine & $329.90 \pm 6.97^{b}$ & $314.33 \pm 11.99^{b}$ & $836.28 \pm 24.04^{\mathrm{a}}$ \\
\hline Total & 2864.59 & 4844.18 & 6341.28 \\
\hline
\end{tabular}

${ }^{1}$ SM-MIX: 10\% skim milk media with $1 \%$ Bokbunja and $1 \%$ red ginseng extract before fermentation

${ }^{2)}$ FSM: $10 \%$ skim milk media fermented by L. acidophilus

${ }^{3}$ FMIX: $10 \%$ skim milk media with $1 \%$ Bokbunja and $1 \%$ red ginseng extract fermented by L. acidophilus

${ }^{3}$ Data are presented as a mean \pm standard deviation. Means with the same alphabet in each column are not significantly different at $\mathrm{p}<0.05 \mathrm{using}$ one-way ANOVA

${ }^{4)} \mathrm{ND}=$ Not detected.

Insulin regulates blood glucose concentrations [22, 23]. Consumption of carbohydrates causes an immediate increase in blood glucose levels, followed by the release of insulin from pancreatic $\beta$ cells. Insulin binds cell surface receptors in the liver, skeletal muscle, and adipose tissues and reduces the blood glucose levels. In addition, insulin can influence plasma leptin concentration; these two hormones act together in the brain to affect the homeostatic systems [24]. In this study, the HFDFMIX group showed reduced plasma insulin levels compared to the HFD group. It is still unclear whether supplementation with the fermented mixture had a direct effect in decreasing 
insulin.

However, multiple studies reported that treatment with red ginseng extract or its functional constituents, saponins, led to a reduction in the mRNA levels of angiogenic factors (e.g., VEGF-A and FGF-2) and matrix metalloproteinases (MMPs) (e.g., MMP-2 and MMP-9), and the expression of hypothalamic neuropeptide Y (NPY) in vivo [2-4, 25]. In addition, immature black raspberry contains large amounts of ellagic acid, which can regulate the protein levels of Nrf2, NF$\kappa \mathrm{B}$ and CPT1 in an HFD-induced rat model of metabolic syndrome [26], and has anti-obesity effects [27]. Therefore, it is speculated that the anti-obesity effect in the HFDFMIX group might be correlated with the presence of various biologically active saponins in the red ginseng extract and phenolic compounds in the black raspberry extract.

L. acidophilus is associated with cholesterol absorbance and regulation of intestinal microflora $[28,29]$. However, in our experiments, L. acidophilus did not appear to exert an antiobesity effect. No significant differences were observed in any obesity-related measurements between the HFD-FSM group and the HFD group.

In terms of free amino acid contents, significant differences were observed between the FSM and FMIX. Arginine exerts an anti-obesity effect, reduces fat content, and inhibits the growth of white adipose tissue [30]. The anti-obesity effect of HFD-FMIX may be attributed to amino acids such as arginine. Therefore, the anti-obesity effect of HFD-FMIX is likely to be attributed to red ginseng saponins, phenolic acids in immature black raspberry, and high content of free amino acids in the FMIX fermented by L. acidophilus.

In conclusion, supplementation with a fermented mixture of skim milk, red ginseng, and immature black raspberry extract had an anti-obesity effect in a mouse model of obesity. This suggests that fermented materials combined with functional edible plant and probiotics could be applied for the development of anti-obesity functional foods.

\section{Acknowledgments}

This research was financially supported by the Ministry of Trade, Industry and Energy (MOTIE) and Korea Institute for Advancement of Technology (KIAT) through research supporting project for convergence of regional specialized technology.

\section{References}

1. Kopelman PG. 2000. Obesity as a medical problem. Nature 404(6778): 635-643. doi: 10.1038/35007508

2. Kim JH, Hahm DH, Yang DC, Kim JH, Lee HJ, et al. 2005. Effect of crude saponin of Korean red ginseng on high-fat diet-induced obesity in the rat.J Pharmacol Sci 97(1): 124-131. doi: 10.1254/jphs. FP0040184

3. Hwang JT, Kim SH, Lee MS, Kim SH, Yang HJ, et al. 2007. Antiobesity effects of ginsenoside $\mathrm{Rh} 2$ are associated with the activation of AMPK signaling pathway in 3T3-L1 adipocyte. Biochem Biophys Res Commun 364(4): 1002-1008. doi: 10.1016/j.bbrc.2007.10.125

4. Hwang JT, Lee MS, Kim HJ, Sung MJ, Kim HY, et al.2009. Antiobesity effect of ginsenoside Rg3 involves the AMPK and PPAR- $\gamma$ signal pathways. Phytother Res 23(2): 262-266. doi: 10.1002/ptr.2606.
5. Cha HS, Lee MK, Hwang JB, Park MS, Park KM. 2001. Physicochemical characteristics of Rubus coreanus Miquel.J Korean Soc Food Sci Nutr 30(6): 1021-1025.

6. Yoon I, Cho JY, Kuk JH, Jang MY, Ahn TH, et al. 2002. Identification and activity of antioxidative compounds from Rubus coreanum fruit. Korean J Food Sci Technol 34(5): 898-904

7. Kim ID, Kang KS, Kwon RH, Yang JO, Lee JS, et al. 2007. The Effect of Rubus coreanum Miquel against lipopolysaccharide-induced oxidative stress and lipid metabolism. Journal of Food Hygiene and Safety 22(3): 213-217.

8. Kwon KH, Cha WS, Kim DC, Shin HJ. 2006. A research and application of active ingredients in Bokbunja (Rubus coreanus Miquel). Korean J Biotechnol Bioeng 21(6): 405-409.

9. Arora T, Anastasovska J, Gibson G, Tuohy K, Sharma RK, et al. 2012. Effect of Lactobacillus acidophilus NCDC 13 supplementation on the progression of obesity in diet-induced obese mice. Br J Nutr 108(8): 1382-1389. doi: $10.1017 / \mathrm{S} 0007114511006957$

10. Lee K, Paek K, Lee HY, Park JH, Lee Y. 2007. Antiobesity effect of trans-10, cis-12-conjugated linoleic acid-producing Lactobacillus plantarum PL62 on diet-induced obese mice. J Appl Microbiol 103(4): 1140-1146. doi: 10.1111/j.1365-2672.2007. 03336.x

11. Akalin AS, Gönç S, Düzel S. 1997. Influence of yogurt and acidophilus yogurt on serum cholesterol levels in mice. J Dairy Sci 80(11): 27212725. doi: 10.3168/jds. S0022-0302(97)76233-7

12. Taranto MP, Medici M, Perdigon G, Holgado PR, Valdez GF. 1998. Evidence for hypocholesterolemic effect of Lactobacillus reuteri in hypercholesterolemic Mice.J Dairy Sci 81(9): 2336-2340. doi: 10.3168/ jds.S0022-0302(98)70123-7

13. Enavall E, Perlmann P. 1972. Enzyme-linked immunosorbent assay, Elisa. III. Quantitation of specific antibodies of enzyme labeled antiimmunoglobulin in antigen-coated tubes. J Immunol 109(1): 129-135.

14. Van Harmelen V, Reynisdottir S, Eriksson P, Thrne A, Hoffstedt J, et al. 1998. Leptin secretion from subcutaneous and visceral adipose tissue in women. Diabetes 47(6): 913-917.

15. Garaulet M, Perex-Llamas F, Fuente T, Zamora S, Tebar FJ. 2000. Anthropometric, computed tomography and fat cell data in an obese population: relationship with insulin, leptin, tumor necrosis factor-alpha, sex hormone-binding globulin and sex hormones. Eur J Endocrinol 143(5): 657-666. doi: 10.1530/eje.0.1430657

16. Maffei M, Halaas J, Ravussin E, Pratley RE, Lee GH, et al. 1995. Leptin levels in human and rodent: measurement of plasma leptin and ob RNA in obese and weight-reduced subjects. Nat Med 1(11): 1155-1161.

17. Ostlund RE, Yang JW, Klein S, Gingerich R. 1996. Relation between plasma leptin concentration and body fat, gender, diet, age, and metabolic covariates. J Clin Endocrinol Metab 81(11): 3909-3913. doi: 10.1210/jcem.81.11.8923837

18. Kim SJ, Park KG, Kim HK, Kim MK, Lee SW, et al. 2004. Serum adiponectin concentration according to visceral fat amount and its relationship of metabolic risk factors in premenopausal obese women. Korean Journal of Medicine 66(3): 259-266.

19. Hotta K, Funahashi T, Bodkin NL, Ortmeyer HK, Arita Y, et al. 2001. Circulating concentrations of the adipocyte protein adiponectin are decreased in parallel with reduced insulin sensitivity during the progression to type 2 diabetes in rhesus monkeys. Diabetes 5(5): 11261133.

20. Fruebis J, Tsao TS, Javorschi S, Ebbets-Reed D, Erickson MR, et al. 2001. Proteolytic cleavage product of $30-\mathrm{kDa}$ adipocyte complementrelated protein increases fatty acid oxidation in muscle and causes weight loss in mice. Proc Natl Acad Sci U S A 98(4): 2005-2010. doi: 10.1073/pnas.98.4.2005

21. Qi Y, Takahashi N, Hileman SM, Patel HR, Berg AH, et al. 2004. Adiponectin acts in the brain to decrease body weight. Nat Med 10(5): 524-529. doi: $10.1038 / \mathrm{nm} 1029$

22. Saltiel AR, Kahn CR. 2001. Insulin signalling and the regulation 
of glucose and lipid metabolism. Nature 414(6865): 799-806. doi: $10.1038 / 414799 a$

23. Kahn SE, Hull RL, Utzschneider KM. 2006. Mechanisms linking obesity to insulin resistance and type 2 diabetes. Nature 444(7121): 840-846. doi: 10.1038/nature05482

24. Könner AC, Klöckener T, Brüning JC. 2009. Control of energy homeostasis by insulin and leptin: targeting the arcuate nucleus and beyond. Physiol Behav 97(5): 632-638. doi: 10.1016/j. physbeh.2009.03.027

25. Lee H, Park D, Yoon M. 2013. Korean red ginseng (Panax ginseng) prevents obesity by inhibiting angiogenesis in high fat diet-induced obese C57BL/6J mice. Food Chem Toxicol 53: 402-408. doi: 10.1016/j. fct.2012.11.052

26. Panchal SK, Ward L, Brown L. 2013. Ellagic acid attenuates highcarbohydrate, high-fat diet-induced metabolic syndrome in rats. Eur J
Nutr 52(2): 559-568, doi: 10.1007/s00394-012-0358-9

27. Jung MA, Cho SH, Lee SY, Kim JH, Kim YS, et al. 2015. Anti-obesity effects on unripe Rubus coreanus Miquel extract in high fat dietinduced obese mice. Int J Biochem Res Rev 5(1): 20-26. doi: 10.9734/ IJBCRR/2015/12680

28. Gilliland SE, Nelson CR, Maxwell C. 1985. Assimilation of cholesterol by Lactobacillus acidophilus. Appl Environ Microbiol 49(2): 377-381.

29. Takiguchi R, Mochizuki E, Suzuki Y, Nakajima I, Benno Y. 1997. Inhibitory effects of Lactobacillus acidophilus SBT 2062 and Bifidobacterium longum SBT 2928 on harmful intestinal bacteria. J Int Microb 11(1): 11-17. doi: 10.11209/jim1997.11.11

30. McKnight JR, Satterfield MC, Jobgen WS, Smith SB, Spencer TE, et al. 2010. Beneficial effects of L-arginine on reducing obesity: potential mechanisms and important implications for human health. Amino Acids 39(2): 349-357. doi: 10.1007/s00726-010-0598-z 